\title{
Traffic-induced vibrations. The impact on buildings and people
}

\author{
Anna Jakubczyk-Galczynska ${ }^{a}$, Robert Jankowski ${ }^{\mathrm{b}}$ \\ ${ }^{a}$ MSc. Gdansk University of Technology, Narutowicza 11/12, Gdansk 80-233, Poland \\ ${ }^{b}$ PhD., DSc., Associate Professor, Gdansk University of Technology, Narutowicza 11/12, Gdansk 80-233, Poland
}

\begin{abstract}
Traffic-induced vibrations have recently been of major concern to engineers as one of the aspects of so called physical environmental pollution. The interest is related to the observations of serious negative effects of such kind of vibrations on buildings and their inhabitants. Traffic-induced vibrations may cause plaster cracks, structural damage and even failure and collapse of the structure. They may also be the reason of serious complaints from people living inside buildings which experience vibrations. The aim of the present paper is to analyze the example of the family house located near a major road with heavy traffic. First, the details concerning the measuring procedure according to Polish standards have been described. Then, the results of the measurements conducted on site have been shown and the impact of traffic-induced vibrations on the structure has been analyses and discussed.
\end{abstract}

Keywords: vibrations; traffic; buildings; noise.

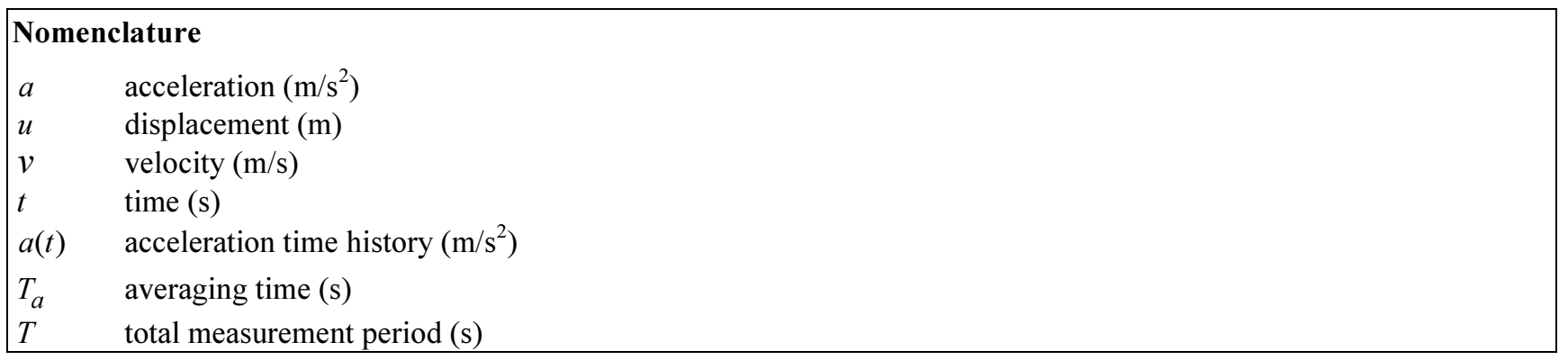

\section{Introduction}

Traffic-inducted vibrations are a common problem of modern-day architectural engineering and pose a great challenge for designers and contactors, as well as for residents of edifices subjected to dynamic interplay. Fortunately, modern technology and constant development of science contribute to solving many engineering problems, including those connected with vibrations. In the present article, authors attempt to describe the problem, picture the reasons and results of vibrating of single-family houses, but above all they try to depict the methodology of performing calculations basing on Polish regulations.

Occurrences of vibrations are related to physical pollution of the environment. Traffic-induced vibrations have a great impact on residents located in their reach. Moreover, traffic induces noise, which may also be a nuisance for the inhabitants.

\section{Structural dynamics and vibrations}

The effect of building vibrations is strictly related to the dynamics of structures. Vibrations can be described as declensions in balance of particles of the building caused by the energy supplied to them. The reach of the dynamic influence, as suggested in [1], is $25 \mathrm{~m}$ from the axis of a tram track and from the outermost car lane, $40 \mathrm{~m}$ from the wall of a subway tunnel and train tracks.

Corresponding author: Anna Jakubczyk-Galczynska. E-mail address: annjakub@pg.gda.pl

http://dx.doi.org/10.3846/enviro.2014.028

(C) 2014 The Authors. Published by VGTU Press. This is an open-access article distributed under the terms of the Creative Commons Attribution License, which permits unrestricted use, distribution, and reproduction in any medium, provided the original author and source are credited. 


\subsection{Causes of vibrations}

There are many reasons for building vibrations [2], some of them are constant dynamic encumbrances, others are temporary. Some of them are easily assessed but others are purely random. The most common causes include: earthquakes [3-5], mining tremors (paraseismic vibrations), large mechanical vibrating entities, air pressure, movement of large masses of people or vibrations resulting from vehicles using the nearby road. The last reason is the one being described in detail in the present article.

Traffic-induced vibrations [1], [6] are caused by the movement of vehicles, utilization, infrastructural structures on road and train tracks. Vibrations induced by movement of large mechanical vehicles or long-lasting usage of heavy appliances are transferred through the ground on the foundations of nearby structures.

\subsection{Effects of vibrations}

When it comes to the effects of traffic-induced vibrations, they may be small and imperceptible; however, they may as well become the reason of a major malfunction or even lead to the collapse of a structure. As it is mentioned in [1], [6], [7], the most common visible effects of traffic are chaps and scratches on the plaster covering the building, falling off the paint and plaster, cracks on the elements of the structure or even building malfunctions and collapses.

Apart from the influence on a building, traffic-induced vibrations also affect people living in places where the vibrations occur. The problem is extremely significant in cases of long-lasting influence of noise and vibrations on people - the problem is approached in a detailed way in chapter 4.

\subsection{Factors influencing vibrations}

It is obvious that vibrations influence building structure, the exact strengths of the aforementioned influence is dependent on some certain factors. These factors are mainly related to the displacement of a building and characteristics of nearby roads:

- Quality and type of pavement: whether it is asphalt, gravel, cobblestone or concrete; is it damaged? (the more the damages of the surface, the bigger the influence of vibrations),

- Type of ground through which the waves travel,

- Type of road: it is of critical importance is the road small and unattended regularly or is it a big communication lane heavily attended by vehicles,

- Maximum allowed speed: the faster the vehicles can move, the bigger vibrations,

- Maximum vehicle weight: the heavier the vehicles are, the stronger vibrations,

- Longevity of vibrations: damage caused by vibrations is the highest when the encumbrances that cause it are constant (over 30 minutes per day); are the vibrations long-lasting - occurring from 3 to 30 minutes per pay or are they shortlasting - occurring below 3 minutes per day,

- Shape and dimensions of the building: it is important whether it is a small, 1 or 2-storey family house which vertical projection does not exceed $15 \mathrm{~m}$ and its height does not exceed the measurement of projection; or it is a multi-storey building below 5 floors and its height is smaller than doubled lowest width,

- Average distance from the axis of the road: the lower the distance, the damage hazard increases.

The mentioned factors decide on the intensity of vibrations transferred on a building. The heavier the utilization of a road gets, the more intensive the damage to a building is done. Local defects may also occur, but more importantly, vibrations can influence the load bearing capacity of the structure.

\section{Defining the influence of vibrations on buildings}

In order to counteract vibrations, first it is essential to establish which buildings are actually endangered. It can be done by using a Polish standard [6]. It needs to be pointed out that a standard may only be used to determine the danger to denselyshaped brick buildings, vertical projection of which should not exceed 15 meters. The building should not exceed two floors and its height must not exceed the measurement of the projection. The danger is assessed through the Dynamic Influence Scale I (DIS I), as described in [6].

There is also the DIS II scale which is used to indicate dynamic influences on buildings of maximum 5 floors, their height being lower than doubled width [6].

The norm [6] suggests that measurements of accelerations or velocity emerging from vehicle movement should be made using specialized measuring equipment. Each of the measurements may be depicted though a graph of filtered accelerations in the form of acceleration time history.

\subsection{Measurement methodology}

The measurement technique differs depending on the analyzed case. There are four possible cases [1]:

- The building is being designed, the vibration source is virtual,

- The building is being designed, the vibration source is being utilized, 
- The building exists, the vibration source is virtual,

- The building exists, the vibration source is being utilized.

In the first case, a calculation model of the building is being created which allows the use of the Finite Element Method [1].The model uses kinematic input. The second instance requires measuring the ground vibrations at the location where the structure will be erected. In the third case, acceleration time histories from similar locations are used. When it comes to the last situation, one needs to measure the vibrations, filter the results and compare them with values defined in standard [6].

Vibration measurements determining the reach of dynamic influences are carried out encumbrances that are short-term (not exceeding 3 minutes per day), long-term (between 3 and 30 minutes per day) and constant (exceeding 30 minutes per day). The sensors should be placed [6,7] in at least 3 places. Measuring points ought to be placed on the foundation or on a wall near the ground level. The sensors must not be placed in places that are separated by movement joints, in places with great vibrations amplitude, e.g. on a ledge under the stair stoop. Sensors placed on the basement ceiling will show inflated values [8]. The measuring should be done for horizontal components of the foundation vibrations or for the bearing walls on the level of ground, separately for horizontal and vertical directions. The results should be converted and prepared properly for further analysis. Time span should only be recognized if the amplitude values are higher than 0.2 of the maximum value $[1,6]$. This process is called frequency data filtering. The case of study is the analysis of bands of $1 / 3$ octaves between $1-100 \mathrm{~Hz}$ frequencies. A third is a frequency band between frequencies with relation equal the cube root of two.

The next three thirds set an octave. The median frequencies of metrological thirds are $[6]: 1 ; 1.25 ; 1.6 ; 2 ; 2.5 ; 3.15 ; 4 ; 5$; $6.3 ; 8 ; 10 ; 12.5 ; 16 ; 20 ; 25 ; 31.5 ; 40 ; 50 ; 63 ; 80 ; 100 \mathrm{~Hz}$. It can be further deduced, that extreme values should be determined for the 21 different median frequencies. Next, they should be marked on the dynamic influence scale graph; the structure may be placed in five different danger zones:

- Zone I: no vibration influence on the building;

- Zone II: vibrations are noticeable but do not pose a threat to the building;

- Zone III: the overall load bearing capacity of the building may be weakened;

- Zone IV: vibrations have major influence on the building; the amplitudes are high enough to cause various objects in the apartments to tremble. The building is in hazard for health and life of its inhabitants;

- Zone V: The load bearing capacity the building is dysfunctional as a result of a massive vibrations amplitude; this may result in a major malfunction or even lead to collapse of the structure.

\subsection{Analysis example of vibration impact on single-family house}

This chapter presents an example concerning the procedure of measurements of vibrations. The measurements were performed in a small town in northern Poland. The structure is one-storey single-family house which was built in the year 1922 (Fig. 1a). The examined house has a plan dimensions of $12.0 \times 9.45 \mathrm{~m}$ and the height of $6.6 \mathrm{~m}$. The foundations are made of stone; ceilings are wooden, wall made out of brick covered by polystyrene plates.
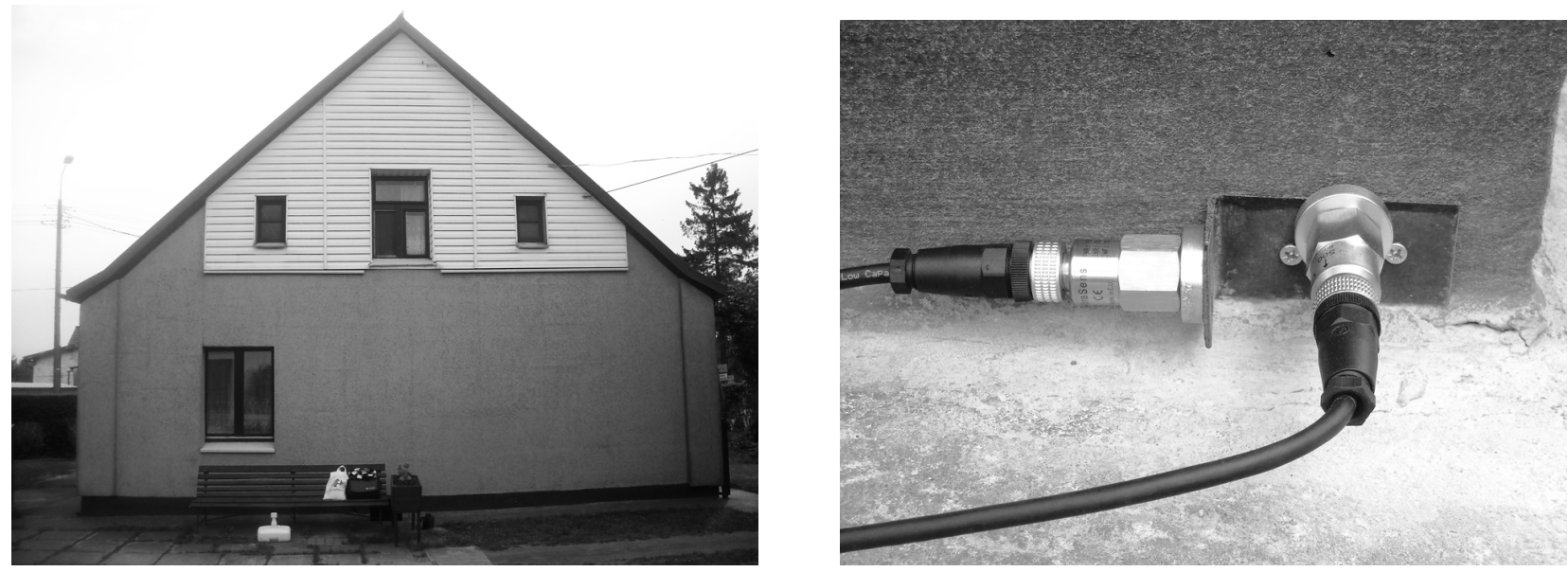

Fig. 1. The examined single-family house: (a) general view of the structure; (b) sensors used in the measurements

The measurements were conducted because the occupants of the house felt the negative vibrations. Furthermore, they noticed cracking of plaster, which may have been caused by traffic-induced vibrations.

Four sensors were installed on the parallel wall towards the street (the distance between the wall and the street edge is $7.35 \mathrm{~m}$ ), see Figure $1 \mathrm{~b}$. The tests were performed in two horizontal directions: X and Y. In total, 17 measurements were conducted at the exact moments when driving a lorry, buses, dustcart and tractor. The measurements were analyzed according to the rules, which were described in the previous chapter (chapter 3.1) and the results were placed on the DIS graph, see Figure 2. 
After the measurements, the following conclusion was obtained: the analyzed building is located in the first phase of dynamic intensity, in that case vibrations caused by driving vehicles in the street near building don't have influence on the structure of building. It could therefore be deduced that damages observed in the building might be caused by wear and fatigue, age of building or faulty workmanship of building's elements.

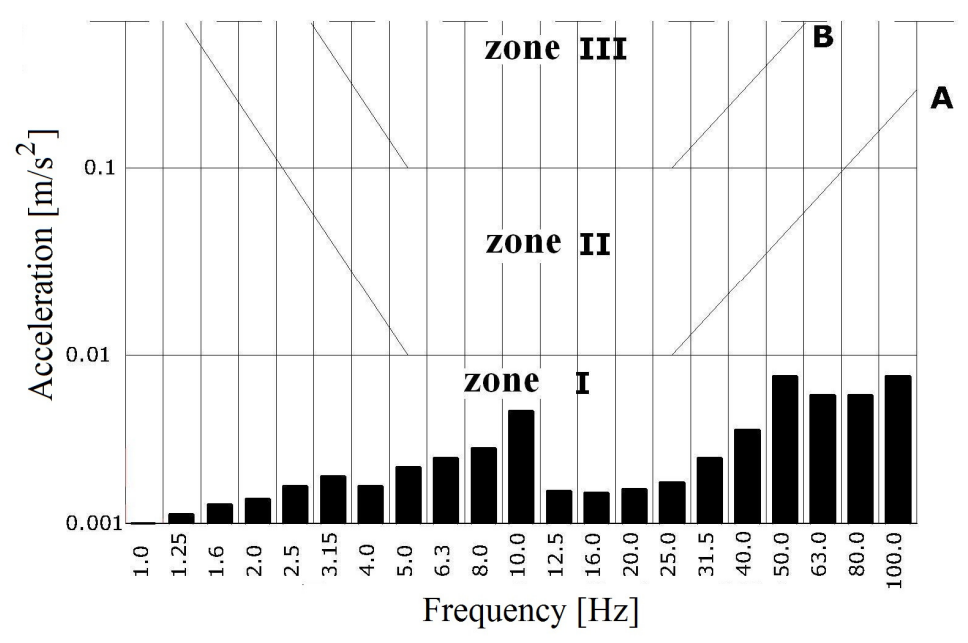

Fig. 2. Peak acceleration with respect to the frequency of oscillations for the measurements in the single-family house

\section{Vibrations. The impact on people}

\subsection{Description of method}

Vibrations which are caused by traffic may also cause discomfort for people, which are in the sphere of influence. After conducting many studies, both in laboratories as well as in real buildings, it has been observed that a threshold noticeability of vibrations by human being is situated lower than the limit for building itself [1]. The estimate of vibrations impact on people assumes that vibrations are received in a passive way [6]. There are generally two situations [1]:

- Sitting or standing position: vibrations are received by foot and seat - the $Z$ axis is going through spine, the $X Y$ axis have horizontal direction.

- Lying position: person receives the vibrations with the aid of the whole body - the $\mathrm{Z}$ axis is going through back to chest, the $\mathrm{Y}$ axis from side to side.

The oscillating quantity is the acceleration (or velocity) Root Mean Square (RMS) value, which is specified according to the formula [1]:

$$
a_{R M S}=\left[\frac{1}{T_{a}} \int_{T_{a}}[a(t)]^{2} d t\right]^{0.5}
$$

It is necessary to remember that vibrations, which have been generated as a result of traffic, have irregular character; first they have increasing and next decreasing trend. For this reason, averaging time is taken into account, which has the value of amplitude bigger than 0.2 peak value [1].

\subsection{Rating parameters and perceptibility vibrations threshold}

Polish standard [9] defines two kinds of rating parameters and one parameter is introduced in European standards [9, 10]. The standard [9] describes the following two methods (chapters 4.2.1 and 4.2.2).

\subsubsection{The adjusted value of acceleration value in frequency band $(1-80 \mathrm{~Hz})$}

The rectification takes place by introducing to measuring trajectory (between the sensor and recorder) the correcting filter the results of rating are adjusted by efficient value of acceleration or velocity. The perceptibility threshold by human being for this parameter has been determined in [6] and this value is equal to $0.005 \mathrm{~m} / \mathrm{s}^{2}(0.0001 \mathrm{~m} / \mathrm{s})$ for the $Z$ axis and $0.0036 \mathrm{~m} / \mathrm{s}^{2}(0.00029 \mathrm{~m} / \mathrm{s})$ for the $\mathrm{X}$ and $\mathrm{Y}$ axes. 


\subsubsection{The Spectrum Value (frequency structure) of acceleration or velocity in $1 / 3$ octane band}

Similarly as in the case of measurements of influence of vibrations on building, it is necessary to record acceleration time history $a(t)$ and then exposed it to filtration and show the results (Fig. 3).
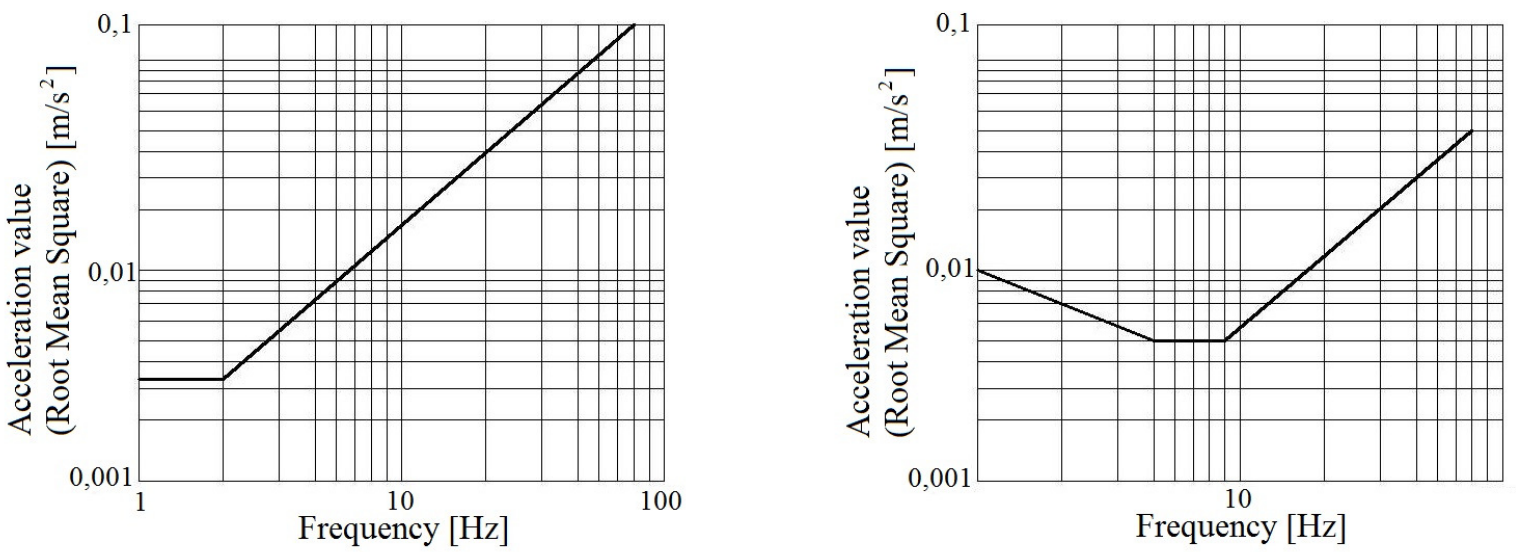

Fig. 3. Perceptibility vibrations threshold for $\mathrm{Z}$ direction (left side) and $\mathrm{X}$ and $\mathrm{Y}$ directions (right side) $[1,6]$

\subsubsection{VDV vibrations dose}

The method, which is described in details in [1], [2], [10], enables us to specify the evaluation of vibrations influence by a reference of full vibration time. VDV vibrations dose has been introduced to European standard [12], [13] after conducting of many tests. It is defined as:

$$
V D V=\left[\int_{0}^{T}[a(t)]^{4} d t\right]^{0.25}\left[\frac{m}{s^{1.75}}\right]
$$

Clear attribute of perceptibility threshold is not present for this parameter. Some interpretations indicate [1], that the residents observations are equivalent to perceptibility threshold and the following maximum values can been accepted: for a day $V D V=0.2-0.4 \mathrm{~m} / \mathrm{s}^{1.75}$ and for a night $V D V=0.13 \mathrm{~m} / \mathrm{s}^{1.75}$.

In the European directive [12], a condition of the impact of vibrations people is stated as equal to one value, e.g. acceleration of mechanical vibrations during a day, which is appointed for three directions $\mathrm{X}, \mathrm{Y}$ and $\mathrm{Z}$. This value should not exceed $0.8 \mathrm{~m} / \mathrm{s}^{2}$.

\subsection{Acceptable noise values in residential structures (housing)}

Occurrence of traffic-induced vibrations have a connection with discomfort and with dangerous noise to human ear. In accordance to the European directive [12] and to the standard [13], acceptable level of noise penetrating housing rooms should not exceed value of $40 \mathrm{~dB}$ during a day (from 6:00 to 22:00) and 30dB during a night (22:00-6:00).

Acceptable noise values of technical furnishings of buildings and another devices in the building and outside the structure should not exceed value of $40 \mathrm{~dB}$ during a day and $30 \mathrm{~dB}$ during a night.

\section{Methods of reduction of vibrations}

There are a number of methods of reduction of traffic-induced vibrations on buildings [14]. The most commonly used are:

- elastic mats between a ground and a building (base-isolation) [15], [16];

- elastic division of the whole building above the underground storey;

- asphalting the road;

- elimination of the water inspection chambers from the path of the road;

- reduction the speed of vehicles.

\section{Summary and conclusions}

The problem of vibrations has recently become very important because more and more areas are being urbanized and new roads are being built, both in towns and in the countryside. Good-connected areas are welcomed and their prices are still increasing, thus more and more buildings are being constructed near the roads. Therefore nowadays, the issue of trafficinduced vibrations in buildings concerns structures (both the existing and the planned ones) on larger scale then in the past. 
For this reason, it is really important to consider a number of activities so as to efficiently decrease the impact of such vibrations on buildings and people.

\section{References}

[1] Kawecki, J.; Stypuła, K. 2013. Ensuring the vibration comfort to people residing in buildings exposed to the impact of communication. Cracow University of Technology Publishing House, ISBN 978-83-7242-710-6.

[2] Kawecki, J. 2011. Dynamic actions on building objects, Folia Scientiarum Universitatis Technicae Resoviensis 276: 115-134.

[3] Jankowski, R. 2007. Assessment of damage due to earthquake-induced pounding between the main building and the stairway tower, Key Engineering Materials 347: 339-344. http://dx.doi.org/10.4028/www.scientific.net/KEM.347.339

[4] Jankowski, R. 2012. Non-linear FEM analysis of pounding-involved response of buildings under non-uniform earthquake excitation, Engineering Structures 37: 99-105. http://dx.doi.org/10.1016/j.engstruct.2011.12.035

[5] Mahmoud, S.; Abd-Elhamed, A.; Jankowski, R. 2013. Earthquake-induced pounding between equal height multi-storey buildings considering soilstructure interaction, Bulletin of Earthquake Engineering 11(4): 1021-1048. http://dx.doi.org/10.1007/s10518-012-9411-6

[6] PN-85 B-02170. 1985, Evaluation of the harmfulness of building vibrations due to ground motion, Polish Committee for Standardization of Measurement and Quality.

[7] Hunaidi, O. 2000. Traffic vibrations in buildings, National Research Council of Canada.

[8] Kawecki, J.; Stypuła, K. 2007. Faults in diagnoses concerning evaluation of dynamic influences on buildings, XXIII Conference on Structural Failures Szczecin-Miedzyzdroje, Poland: 267-274.

[9] PN-88 B-02171. 1988, Evaluation of vibration influence on people in buildings. Polish Committee for Standardization of Measurement and Quality

[10] BS 6472-1:2008. Guide to evaluation of human exposure to vibration in buildings, Part.1: Vibration sources other than blasting, British Standard, 2008.

[11] ISO 10137.2007. Bases for design of structures. Serviceability of buildings and walkways against vibration, 2007.

[12] Directive 2002/49/EC of the European Parliament and of the Council of 25 June 2002 relating to the assessment and management of environmental noise.

[13] PN-87/B-02151/02. 1987. Building acoustics. Protection against noise spaces in buildings. Permissible sound levels in the room.

[14] Engel, Z. 2001. Environmental protection against vibrations and noise, PWN, Warsaw.

[15] Jankowski, R. 2003. Nonlinear rate dependent model of high damping rubber bearing, Bulletin of Earthquake Engineering 1(3): $397-403$. http://dx.doi.org/10.1023/B:BEEE.0000021512.74990.45

[16] Mahmoud, S.; Austrell, P-E.; Jankowski, R. 2012. Simulation of the response of base-isolated buildings under earthquake excitations considering soil flexibility, Earthquake Engineering and Engineering Vibration 11: 359-374. http://dx.doi.org/10.1007/s11803-012-0127-z 